\title{
Optimization of Thermal Conditions of Heat Recovery Boilers with Regenerative Heating in the High-Temperature Section of Isoamylene Dehydrogenation
}

\author{
D.S. Balzamov ${ }^{1 *}$, I.G. Akhmetova ${ }^{2}$, V.V. Bronskaya ${ }^{3}$, O.S. Kharitonova4, \\ E.Yu. Balzamova ${ }^{5}$
}

${ }^{1}$ Department of Power Supply of Enterprises and Energy Resource Saving Technologies, Kazan State Power Engineering University, Krasnoselskaya St., 51, Kazan, Russian Federation, 420066

${ }^{2}$ Department Economics and Organisation Production, Kazan State Power Engineering University, Krasnoselskaya St., 51, Kazan, Russian Federation, 420066

${ }^{3}$ Department of Chemical Process Engineering, Kazan National Research Technological University, Karl Marx St., 68, Kazan, Russian Federation, 420015

${ }^{4}$ Department of Chemical of Petroleum and Gas Processing, Kazan National Research Technological University, Karl Marx St., 68, Kazan, Russian Federation, 420015

${ }^{5}$ Department Economics and Organisation Production, Kazan State Power Engineering University, Krasnoselskaya St., 51, Kazan, Russian Federation, 420066

\begin{abstract}
Improving the efficiency of use of energy resources at large-capacity energy-consuming enterprises in the petrochemical industry in conditions of high internal and external competition is the priority for the development of the fuel and energy industry. This is confirmed by various legislative acts, including the energy strategy of the Russian Federation for the period up to 2035. This research focuses on a high-temperature section of dehydrogenation of isoamylenes into isoprene, the production of which relates (isoprene production relates to large petrochemical enterprises that consume a huge amount of energy resources) to large-capacity energy-consuming industries. To increase the thermodynamic efficiency of the research object, regenerative feedwater heating for heat recovery boilers is proposed due to deeper cooling of fuel and contact gas (the term "contact gas" is used in the technological regulations of an isoprene production company), which are secondary thermal energy resources in this technology. In accordance with the industry's technology regulations, a block diagram of the initial and improved high-temperature section with the indication of material flows (The term "material flow" refers to the type of substances that are used in the high-temperature dehydrogenation stage of isoamylenes) was developed. The balance equations of the section under consideration are provided, and the thermal efficiency and exergy efficiency for systems utilizing fuel and contact gas are determined. The estimated economic effect was determined in physical terms; it was found to be 2008.58 toe $/ \mathrm{h}$. An exergy flow diagram is also provided to show how the system utilizes contact gas.
\end{abstract}

Keywords: Energy efficiency; Energy technological combination; Heat recovery boiler;

Regenerative heating 


\section{Introduction}

The petrochemical industry is characterized by high energy intensity. Thermal energy costs reach 30-40\%, making it difficult for enterprises in this industry to save energy. This is particularly problematic given the rapid increase in fuel prices currently observed both in Russia and around the world (García-Olivares, 2015; Shkrabets and Berdnyk, 2016).

One of the most promising areas of energy savings in the industry is the organization and improvement of energy technology complexes, where building energy in main technological processes can significantly reduce fuel and energy consumption without changing the structure and parameters of the processing line or affecting established product indicators (Balzamov and Konakhina, 2010).

The application of the principle of energy technological combination (This principle implies the joint elaboration of a technological product and an energy resource) (ETC) becomes an indispensable prerequisite when designing new productions in the petrochemical industry. The ETC principle can be implemented at existing enterprises by having systems utilize secondary energy resources (SERs) not used in the main production processes (Patrascu and Minciuc, 2012; Kosasih and Ruhyat, 2016; Ketoeva et al., 2019). A promising direction for fuel and energy optimization at industry is the introduction of regenerative heating in heat transfer agents utilizing the heat rejected into the environment (Kusumah et al., 2019; Kusrini and Kartohardjono, 2019).

Organic synthesis enterprises have many SERs, and their utilization can significantly reduce fuel consumption. At present, their actual use in relation to their potential use is currently about $40 \%$. The beneficial use of SERs at Russian enterprises is about $40 \%$ (Nazmeen and Konakhina, 2002). This is because most SERs produced at petrochemical enterprises are low-temperature thermal SERs, which cannot be used in high-temperature heat technologies. Therefore, the implementation of low-potential SERs in energy balance in petrochemical industries is a topical issue.

Isoamylenes undergo dehydrogenation to produce isoprene, in accordance with the accepted classification (Nazmeen and Konakhina, 2002) has a classification of technological processes by temperature regime. These processes are subdivided into high-temperature, medium-temperature and low-temperature (Nazmeen and Konakhina, 2002), is related to the high-temperature stage of isoamylenes, since the temperature of the main technological process exceeds $800^{\circ} \mathrm{C}$. Dehydrogenation of isoamylenes into isoprene is related to this stage. Figure 1 shows a diagram of the high-temperature section of the dehydrogenation stage; the numbers label the material flow connecting the elements of the section. Flow parameters are presented in Table 1.

The process of dehydrogenation is as follows. The feed stock is isoamylene. Before entering the furnace, isoamylene undergoes the previous heating stage at the evaporation station, which includes the elements ES1-ES3. Fuel supplied to the furnace burners is a mixture of natural gas and absorption gas (i.e., SER in the main production process); it is also preheated in the fuel heater (FH) and absorption gas heater (AGH) heat exchangers, respectively.

The raw material is evaporated in the oven and overheated to a temperature of $530^{\circ} \mathrm{C}$. Then, the raw material mixed with water vapor is fed to reactor $\mathrm{R}$, where the contact gas is formed in the catalyst layer. The contact gas is sent to the next stages of production for cooling and treatment.

As can be seen from Table 1, during the intermediate stage, the process ovens and contact gas make the flue gases' temperatures sufficiently high, which allows the system to generate water vapor (of required parameters in Table 1) from the heat contained in the gases. 


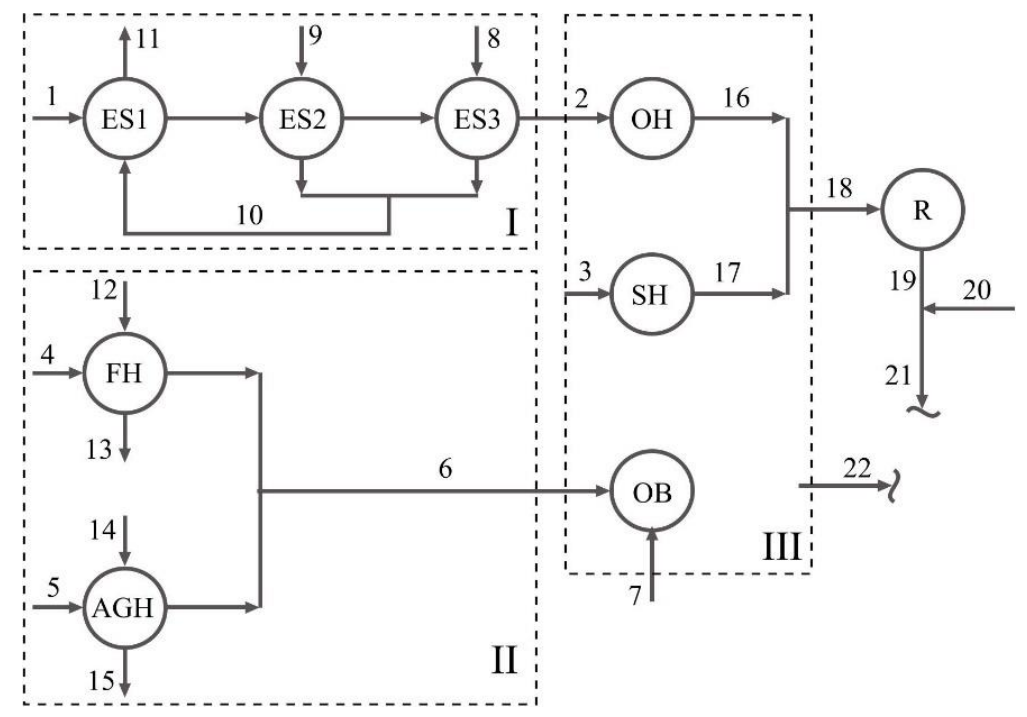

Figure 1 High-temperature section of the dehydrogenation stage of isoamylene to isoprene: I - raw material evaporation station; II - fuel and absorption gas heating station; III - main process unit; ES1, ES2, ES3 - heat exchangers at the evaporation station; FH - fuel heater; AGH - absorption gas heater; $\mathrm{OB}$ - oven burners; $\mathrm{SH}$ - steam heater; $\mathrm{OH}$ - raw material overheater; $\mathrm{R}$-reactor

Table 1 Material flow of the high-temperature section of the dehydrogenation stage of isoamylene into isoprene

\begin{tabular}{clrrr}
\hline $\begin{array}{c}\text { Flow } \\
\text { number }\end{array}$ & \multicolumn{1}{c}{ Heat transfer agent } & $\begin{array}{r}\text { Heat transfer agent flow, } \\
\mathrm{kg} / \mathrm{s}\end{array}$ & $\begin{array}{c}\text { Temperature, } \\
{ }^{\circ} \mathrm{C}\end{array}$ & $\begin{array}{r}\text { Pressure, } \\
\mathrm{MPa}\end{array}$ \\
\hline 1 & Raw material, & 4.44 & 20 & 0.45 \\
2 & Vapor of isoamylene fraction & 4.44 & 105 & 0.4 \\
3 & Water vapor & 23.46 & 158 & 0.6 \\
4 & Fuel gas & 0.84 & 20 & 0.45 \\
5 & Absorption gas & 0.42 & 20 & 0.45 \\
6 & Fuel mixture & 1.26 & 80 & 0.4 \\
7 & Air in the combustion process & 14.36 & 20 & 0.12 \\
8 & Steam & 0.159 & 158 & 0.6 \\
9 & Steam & 0.600 & 158 & 0.6 \\
10 & Condensate & 0.759 & 158 & 0.55 \\
11 & Condensate & 0.759 & 158 & 0.55 \\
12 & Blowdown condensate & 0.217 & 158 & 0.55 \\
13 & Blowdown condensate & 0.217 & 80 & 0.5 \\
14 & Blowdown condensate & 0.108 & 158 & 0.6 \\
15 & Blowdown condensate & 0.108 & 80 & 0.5 \\
16 & Vapor of isoamylene fraction & 4.44 & 500 & 0.5 \\
17 & Overheated steam & 23.46 & 700 & 0.5 \\
18 & Contact gas (a mixture of vapor) & 27.90 & 680 & 0.45 \\
19 & Contact gas & 27.90 & 650 & 0.45 \\
20 & Condensate & 2.42 & 158 & 0.6 \\
21 & Contact gas & 30.32 & 530 & 0.4 \\
22 & Fuel gases & 16.82 & 450 & 0.1 \\
23 & Contact gas & 30.32 & 155.4 & 0.4 \\
24 & Feedwater & 5.5 & 30 & 2.5 \\
25 & Feedwater & 5.5 & 64.9 & 2.5 \\
26 & Steam & 310 & 2.5 \\
27 & Feedwater & 30 & 2.5 \\
28 & Feedwater & 12.64 & 84.9 & 2.5 \\
29 & Steam & 12.64 & 135.5 & 2.5 \\
30 & Fuel gas & 12.01 & 0.1 \\
\hline & & 16.82 & &
\end{tabular}


Thus, at production, it is proposed to organize two heat utilization units that have the same structure and purpose, but differ in load and temperature conditions. Thus, it is necessary to create two heat recovery units at the production site that have the same design and purpose, but differ in load and temperature conditions.

\section{Methods}

Heat utilization was optimized using energy parameters by considering certain conditions.

1. The construction of the main technological elements does not change when solving the optimization problem. Their load value is constant and corresponds to the nominal values specified in the technical specifications of the stage. These elements are a tube heater, a reactor, a raw material evaporation station, and a fuel and absorption gas heating station.

2. Watertube boilers are used for the production of steam. These boilers specify more severe requirements for the feedwater.

3. It is assumed that all steam generated by the heat recovery boilers is used for the needs of the plant.

4. The minimum temperature of gases at the outlet of heat exchangers HE1 and HE2 is limited by the dew point $\left(120^{\circ} \mathrm{C}\right)$.

The heat of the contact gas is utilized in heat recovery boiler U1 to generate saturated steam with a pressure of $2.5 \mathrm{MPa}$. The heat of the flue gases is utilized in heat recovery boiler U2 to generate steam with similar parameters.

The flue gases at the outlet of $\mathrm{U} 2$ have a temperature of $135.5^{\circ} \mathrm{C}$, and the temperature of the contact gases is $155.4^{\circ} \mathrm{C}$. This potential is reduced to $120^{\circ} \mathrm{C}$ in heat exchangers $\mathrm{HE} 1$ and HE2, and the rejected heat is transferred to the feedwater. The heated feedwater enters the heat recovery boiler to generate steam. The utilization of the heat from the contact gas makes it possible to reduce the heat load on the scrubber, an element of the mediumtemperature stage in the production of isoprene. It cools the contact gas to reduce the load on the circulation water supply system in the isoamylenes dehydrogenation unit.

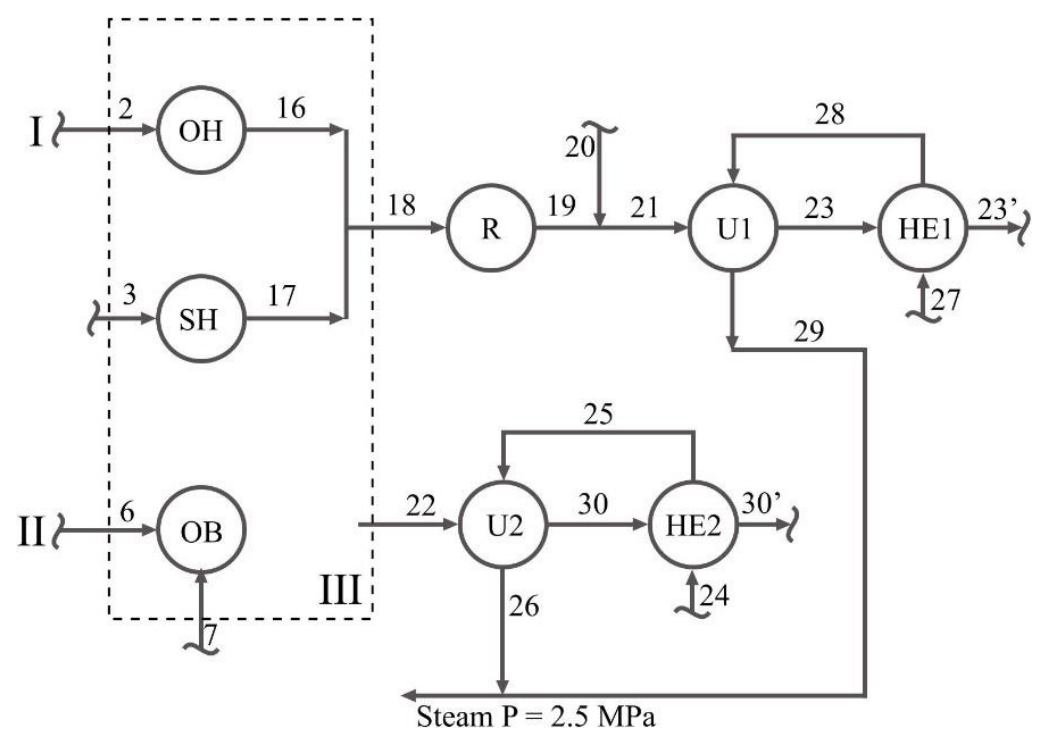

Figure 2 Optimized high-temperature section of isoamylene dehydrogenation to isoprene. U1, U2 heat recovery boilers; HE1, HE2 - heat exchangers; 30', 23' - flue gas flow and contact gas flow, respectively, whose temperatures are lower compared to the original scheme 
The thermal efficiency of the section directly depends on the temperature of the gases that are drawn from the system. In other words, the lower the temperature of the gases at the outlet of the system, the higher the efficiency. Moreover, the output temperature minimum should be between $120^{\circ} \mathrm{C}$ and $180^{\circ} \mathrm{C}$ to prevent exhaust gasses from losing moisture (Konakhina et al., 2011). The exhaust gases' temperature depends on the feedwater temperature, which may be higher (but not lower) than the recommended $120^{\circ} \mathrm{C}$. When optimizing regenerative feedwater heating, it is necessary to find a combination of parameters that will ensure the lowest possible exhaust gas temperature.

To organize the upward pull of combustion products, the gas temperature in front of the flue gas duct must be higher than $250^{\circ} \mathrm{C}$. Since the recommended temperature is much lower, there is no upward pull; therefore, flue gas pumps must be installed.

The method of solving this problem is as follows. Figure 3 shows a diagram of the heat recovery boiler with a regenerative heat exchanger, where installation elements are system units and heat transfer agent flows are connections. Each connection is determined by its corresponding parameters (i.e., pressure, flow rate, and flow temperature). At first, optimizing the considered scheme (Figure 3) may seem simple, but with a more thorough analysis, some difficulties arise due to the boundary conditions imposed on some parameters.

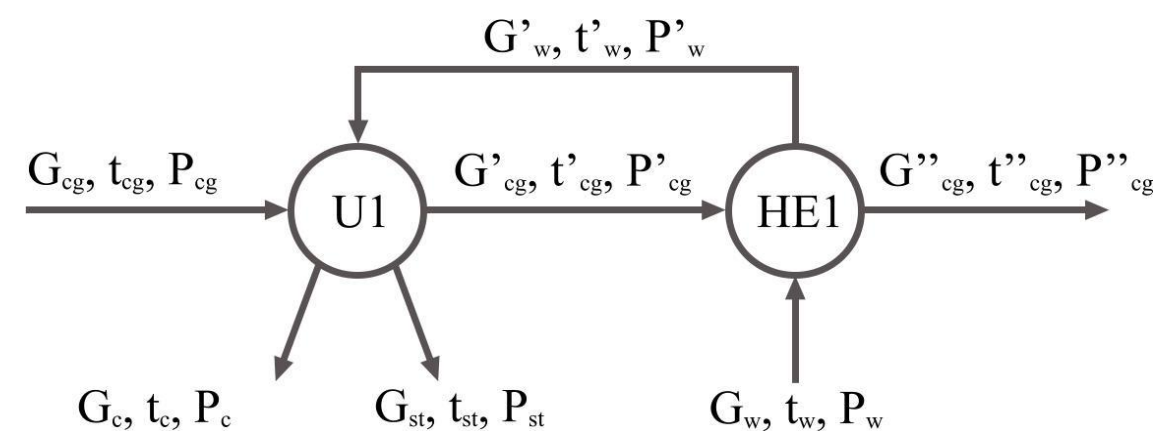

Figure 3 Information diagram of the heat recovery boiler with regenerative feedwater heating

$G_{\mathrm{cg}}, t_{\mathrm{cg}}, P_{\mathrm{cg}}-$ flow rate, temperature, and pressure of the contact gas at the inlet to the heat recovery boiler (U1); $G_{\mathrm{cg},}^{\prime} t_{\mathrm{cg},}^{\prime} P_{\mathrm{cg}}^{\prime}$ - flow rate, temperature, and pressure of the contact gas at the inlet to the heat exchanger (HE1); $G^{\prime \prime}{ }_{\mathrm{cg}}, t^{\prime \prime}{ }_{\mathrm{cg}}, P^{\prime \prime}{ }_{\mathrm{cg}}$ - flow rate, temperature and pressure of the contact gas at the outlet of the heat exchanger (HE1); $G_{\mathrm{w}}, t_{\mathrm{w}}, P_{\mathrm{w}}$ - flow rate, temperature and pressure of feedwater at the inlet to the heat exchanger (HE1); $G_{\mathrm{w}}^{\prime}, t_{\mathrm{w}}^{\prime}, P^{\prime}{ }_{\mathrm{w}}$ - flow rate, temperature and pressure of feedwater at the inlet to the heat recovery boiler (U1); $G_{c}, t_{c}, P_{c}$ - flow rate, temperature and pressure of the condensate at the outlet of the heat recovery boiler (U1); $G_{\mathrm{st}}, t_{\mathrm{st}}, P_{\mathrm{st}}$ - flow rate, temperature and pressure of the steam at the outlet of the heat recovery boiler (U1).

The number of equations connecting the parameters of incoming and outgoing connections of each unit ( $\left.n_{\text {n.e. }}\right)$ and the number of independent parameters included in them $\left(n_{\text {i.p. }}\right)$ are determined. These values can be obtained using the following equations (Nazmeen and Konahina, 2002):

$$
\begin{gathered}
n_{\text {i.p. }}=n_{\text {n.p. }}^{\prime}+n_{\text {n.c. }}-n_{\text {u.p. }} \\
n_{\text {n.e. }}=n_{\text {t.n.p. }}-n_{\text {i.p. }}
\end{gathered}
$$

where $n_{\text {n.p. }}^{\prime}$ is the total number of parameters for incoming connections; $n_{\text {u.p. }}$ is the number of uncertainties in the parameters of the unit's outgoing connections; $n_{\text {n.c. }}$ is the number of 
conditions imposed on the parameters of incoming connections; and $n_{\text {t.n.p. }}$ is the total number of unit parameters.

Thus, the number and type of equations that represent the mathematical model of an object depend on the problem and the limiting conditions that need to be considered. Each unit is sequentially presented below:

$$
\begin{aligned}
& \mathrm{U} 1: n_{\text {n.p. }}^{\prime}=6 ; n_{\text {u.p. }}=2 ; n_{\text {n.c. }}=5 ; n_{\text {t.n.p. }}=15 ; n_{\text {i.p. }}=6+5-2=9 ; n_{\text {n.e. }}=15-9=6 \\
& \text { HE1: } n_{\text {n.p. }}^{\prime}=6 ; n_{\text {up. }}=2 ; n_{\text {n.c. }}=4 ; n_{\text {t.n.p. }}=12 ; n_{\text {i.p. }}=6+4-2=8 ; n_{\text {n.e. }}=12-8=4
\end{aligned}
$$

The balance equations for pressure, material, and energy flow are presented in Table 2.

\begin{tabular}{|c|c|c|}
\hline Element & $\begin{array}{c}\text { Material } \\
\text { balance }\end{array}$ & $\begin{array}{c}\text { Loss of } \\
\text { pressure }\end{array}$ \\
\hline $\mathrm{U}$ & $\begin{array}{c}G_{\text {кг }}^{\prime}=G_{\text {кг }} \\
G_{\text {пв }}=G_{\text {п }}+G_{\text {кп }} \\
G_{\text {П }}=\operatorname{var}\end{array}$ & $\begin{array}{l}P_{\text {кг }}^{\prime}=P_{\text {кг }} \\
P_{\text {п }}=\text { var }\end{array}$ \\
\hline HE & $\begin{array}{l}G_{\text {пв }}^{\prime}=G_{\text {пв }} \\
G_{\text {кг }}^{\prime \prime}=G_{\text {кг }}^{\prime}\end{array}$ & $P_{\text {кг }}^{\prime \prime}=P_{\text {кг }}^{\prime}$ \\
\hline
\end{tabular}

Table 2 Balance equations of the system's high-temperature section

The energy balance equation for the heat recovery boiler $(\mathrm{U})$ is as follows:

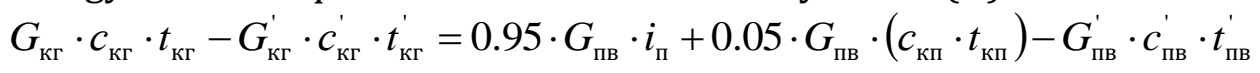

The energy balance equation for the regenerative heater (HE) is as follows:

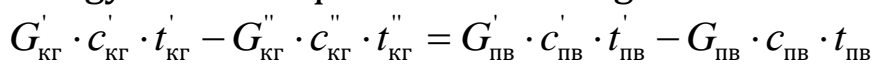

\section{Results and Discussion}

In addition to the material flow parameters (see Table 2), heat transfer, exergy temperature function, and exergy of the heat transfer were determined to assess energy efficiency. The calculation results are presented in Table 3 , and their values were determined as follows.

Heat energy was determined by the expression $Q=G^{*} C_{p} \cdot t$, where $G$ is the flow rate of the material flow $(\mathrm{kg} / \mathrm{s}), c_{\mathrm{p}}$ is the heat capacity at constant pressure for the material flow $\left(\mathrm{kJ} /\left(\mathrm{kg} \cdot{ }^{\circ} \mathrm{C}\right)\right)$, and $t$ is the temperature of the material flow $\left({ }^{\circ} \mathrm{C}\right)$.

The exergy of the heat flow was determined by the expression $E_{q}=\tau \cdot Q$, where $\tau$ is the exergy temperature function that determines the value of the heat contained in the material flow, which is determined by the expression $\tau=1-\frac{T_{0}}{T}$, where $T_{0}$ is the environment temperature under normal conditions (273.15 K) and $T$ is the temperature of the material flow $(\mathrm{K})$.

An exergetic analysis of utilization schemes were performed, and its results can be found in Table 3.

The effectiveness of the proposed solution for organizing the scheme of energytechnological combination was estimated using the exergy efficiency. The methodological recommendations for this coefficient are expounded in Ulum et al. (2017), Nasruddin et al. (2018), and Djubaedah et al. (2018). 
The exergetic efficiency of the proposed scheme of energy technological combination, which is operated on contact and flue gas, respectively, is

$$
\eta_{e x}^{\text {c.g. }}=\frac{E_{\text {u.f. }}}{E_{\text {in }}}=\frac{19993}{29855}=0.67(67 \%)
$$

where $E_{\text {in }}$ is the sum of the exergy of the heat transfer supplied to the system (U1-HE1) by contact gas and feedwater $\left(E_{\text {in }}=29697.74+157.19=29855\right)$, and $E_{\text {u.f. }}$ is the sum of the exergy of the heat flows obtained in the system (U1-HE1) for further beneficial use in the form of steam and condensate $\left(E_{\text {u.f. }}=19776.88+216.1=19993\right)$.

$$
\eta_{e x}^{\text {c.p. }}=\frac{E_{\text {u.f. }}}{E_{\text {in }}}=\frac{3660}{13259.19}=0.276(27.6 \%)
$$

where $E_{\text {in }}$ is the sum of exergy of the heat flows supplied to the system (U2-HE2) by flue gas and feedwater $\left(E_{\text {in }}=13190.79+68.4=13259.19\right)$, and $E_{\text {u.f. }}$ is the sum of exergy of the heat flows obtained in the system (U2-HE2) for further beneficial use in the form of steam and condensate $\left(E_{\text {u.f. }}=3426.96+233.05=3660\right)$.

The thermal efficiency of the utilization industries is

$$
\eta_{\mathrm{h}}^{\text {c.g. }}=\frac{Q_{\text {u.f. }}}{Q_{\text {in }}}=\frac{37672.9}{46582.53}=0.809(80.9 \%)
$$

where $Q_{\text {in }}$ is the sum of the heat flows supplied to the system (U1-HE1) by contact gas and feedwater $\left(Q_{\text {in }}=44994.9+1587.63=46582.53\right)$, and $Q_{\text {u.f. }}$ is the sum of the heat flows obtained in the system (U1-HE1) for further beneficial use in the form of steam and condensate $\left(Q_{\text {u.f. }}=37193.3+479.6=37672.9\right)$.

$$
\eta_{\mathrm{h}}^{\text {c.p. }}=\frac{Q_{\text {u.f. }}}{Q_{\text {in }}}=\frac{6962.1}{21884.02}=0.318(31.8 \%)
$$

where $Q_{\text {in }}$ is the sum of the heat flows supplied to the system (U2-HE2) by flue gas and feedwater $\left(Q_{\text {in }}=21193.2+690.82=21884.02\right)$, and $Q_{\text {u.f. }}$ is the sum of the heat flows obtained in the system (U2-HE2) for further beneficial use in the form of steam and condensate $\left(Q_{\text {u.f. }}\right.$ $=6444.9+517.2=6962.1$ ).

Figure 4 shows the exergetic flow distribution of the system. In Figure 4, the following designations are used: $E_{\text {c.g. }}$-exergy of contact gas entering the utilization system; $E_{\text {c.g. }}^{\prime}$ exergy of the contact gas leaving the system; $E_{\text {st }}$ - exergy of the steam released from the heat recovery boiler; $E_{\mathrm{c}}$ - exergy of the blowdown condensate; $E_{\mathrm{w}}$ - exergy of the feed water.

The diagram of the distribution of exergetic flows (Figure 4) in the thermal energy utilization system (U-HE) allows visualization of the flows from the point of their rational use. The greatest loss of exergy occurs in the heat recovery boiler. According to the energy balance equation, the presence of regenerative feedwater heating in front of the heat recovery boiler partially compensates for the $1608.38 \mathrm{~kJ} / \mathrm{s}$ loss, ensuring more efficient use of the heat of the contact gas. The exergetic flow distribution for a flue gas system will be approximately the same. 
Table 3 Calculation results for the thermal exergy of a system that generates steam at a pressure of $2.5 \mathrm{Mpa}$

\begin{tabular}{|c|c|c|c|c|c|c|c|c|}
\hline Unit & Flow & Direction & $\begin{array}{c}\text { Flow rate, } \\
\mathrm{kg} / \mathrm{s}\end{array}$ & $\begin{array}{c}\text { Temperat } \\
\text { ure, }{ }^{\circ} \mathrm{C}\end{array}$ & $\begin{array}{c}\text { Pressure, } \\
\mathrm{MPa}\end{array}$ & $\begin{array}{l}\text { Heat, } \\
\mathrm{kJ} / \mathrm{s}\end{array}$ & $\begin{array}{l}\text { Temperature } \\
\text { function }\end{array}$ & $\begin{array}{l}\text { Thermal } \\
\text { exergy }\end{array}$ \\
\hline \multirow{4}{*}{ HE1 } & Feed water & Input & 12.64 & 30 & 2.50 & 1587.63 & 0.10 & 157.19 \\
\hline & Contact gas & Output & 30.32 & 120 & 0.40 & 8732.16 & 0.31 & 2666.31 \\
\hline & Feed water & Input & 12.64 & 84.9 & 2.50 & 3650.38 & 0.24 & 866.24 \\
\hline & Steam & Output & 12.01 & 310 & 2.50 & 37193.3 & 0.53 & 19776.88 \\
\hline \multirow[t]{3}{*}{$\mathrm{U} 1$} & \multirow{2}{*}{ Contact gas } & Input & 30.32 & 530 & 0.40 & 44994.9 & 0.66 & 29697.74 \\
\hline & & Output & 30.32 & 155.4 & 0.40 & 11782.4 & 0.36 & 4274.69 \\
\hline & Condensate & Output & 0.63 & 223.9 & 2.50 & 479.6 & 0.45 & 216.10 \\
\hline \multirow{4}{*}{ HE2 } & Feed water & Input & 5.50 & 30 & 2.50 & 690.82 & 0.10 & 68.40 \\
\hline & Fuel gas & Output & 16.82 & 120 & 0.10 & 8477.28 & 0.31 & 2588.48 \\
\hline & Feed water & Input & 5.50 & 64.9 & 2.50 & 1499.19 & 0.19 & 287.95 \\
\hline & Steam & Output & 4.95 & 310 & 2.50 & 6444.90 & 0.53 & 3426.96 \\
\hline \multirow[t]{3}{*}{$\mathrm{U} 2$} & \multirow{2}{*}{ Fuel gas } & Input & 16.82 & 450 & 0.10 & 21193.2 & 0.62 & 13190.79 \\
\hline & & Output & 16.82 & 135.5 & 0.10 & 9574.38 & 0.33 & 3176.31 \\
\hline & Condensate & Output & 0.55 & 223.9 & 2.50 & 517.2 & 0.45 & 233.05 \\
\hline
\end{tabular}

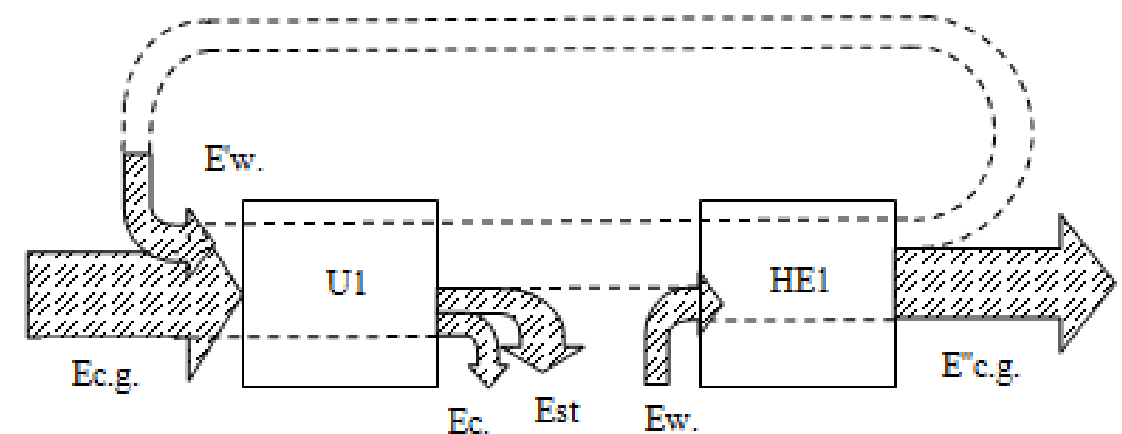

Figure 4 Exergetic flow distribution in the heat utilization industry of the contact gas in the high temperature section

To calculate the economic efficiency, the total amount of heat energy, which was using the heat of the contact and flue gas, was determined. The fuel economy was also calculated (Balzamov et al., 2020a; Balzamov, et al., 2020b). The heat saved $(\mathrm{kW} / \mathrm{h})$ when implementing a regenerative feedwater heating system can be determined using the following equation:

$$
Q_{\text {econ }}=\frac{Q_{\text {uf }}^{\text {c.g. }}+Q_{\text {uf. }}^{\text {c.p. }}}{\eta_{\mathrm{bh}} \cdot \eta_{\mathrm{h}}}=\frac{37672.89+6962.1}{0.8 \cdot 0.95}=58730.25,
$$

where $Q_{\mathrm{uf}}$ is the beneficial use of thermal SER $(\mathrm{kW}), \eta_{\mathrm{bh}}$ is the thermal efficiency of the replaced boiler house (the term "boiler house") that generates steam or hot water, $\eta_{\mathrm{h}}$ is the heat flow coefficient that considers heat loss to the environment during the heat transfer process in the utilization industry.

The fuel economy (ton of fuel equivalent) for contact and flue gases is

$$
\Delta B_{\mathrm{cf}}^{\mathrm{g}}=0.0342 \cdot Q_{\mathrm{econ}}=0.0342 \cdot 58730.25=2008.58
$$

where 0.0342 is the coefficient for converting the heat energy into ton of fuel equivalent. 
The economic efficiency values from Equations 7 and 8 allow future reports to conduct detailed economic analyses on the activity of the isoprene synthesis unit in monetary terms.

\section{Conclusions}

The proposed schemes give the opportunity (to the industries) to save a significant amount of heat energy (i.e., $58730.25 \mathrm{~kW} / \mathrm{h}$ ) in the production of isoprene and achieve a reduction in its cost. The efficiency of energy technological schemes was evaluated using thermal and exergetic efficiencies, the values of which were high: $\eta_{\mathrm{h}}^{\text {c.g. }}=0.809(80.9 \%)$; $\eta_{\mathrm{h}}^{\text {c.p. }}=0.318(31.8 \%)$, and $\eta_{e x}^{\text {c.g. }}=0.67(67 \%) ; \eta_{e x}^{\text {c.p. }}=0.276(27.6 \%)$, respectively.

The suggested option of energy technological combination based on SERs can be extended not only to the production of isoprene, but also to other stages of petrochemical production characterized by a high yield of high-temperature SERs. Regenerative feedwater heating can also be quite effective in other industries such as the production of ethylene, butadiene, ethanol and other organic products.

\section{Acknowledgements}

The study was carried out within the framework of a scientific project of the Russian Science Foundation (RSF) No 18-79-10136.

\section{References}

Balzamov, D.S., Balzamova E.Y., Bronskaya, V.V., Rybkina, E.A., Kharitonova, O.S., 2020b. Beneficial Use of Thermal Secondary Energy Resources in the Rectification Cycle at Ethylene Glycol Production Unit. IOP Conference Series: Materials Science and Engineering, Volume 919, p. 62027

Balzamov, D.S., Balzamova, E.Y., Bronskaya, V.V., Oykina, G.I., Rybkina, E.A., Shaikhetdinova, R.S., Kharitonova, O.S., 2020a. The Beneficial Using the Heat of the Exhaust Gases of the Furnaces of the Technological Unit for the Ethylene Oxide Production. IOP Conference Series: Materials Science and Engineering, Volume 862, p. 62044

Balzamov, D.S., Konakhina, I.A., 2010. System of Energy Technological Combination of HighTemperature Section of Isoamylene Dehydrogenation in Isoprene. Bulletin of Kazan State Power Engineering University, Volume 1(4), pp. 16-25

Djubaedah, E., Rachmat, A., Aisyah, N., Nasruddin., Kurniawan, A., 2018. Multipurpose Optimization of Double Layer Solar Adsorption Chiller based on Exergy and Economy. International Journal of Technology, Volume 9(6), pp. 1276-1284

García-Olivares, A., 2015. Substitutability of Electricity and Renewable Materials for Fossil Fuels in a Post-Carbon Economy. Energies, Volume 8(12), pp. 13308-13343

Ketoeva, N., Soldatova, N., Ilyashenko, S., 2019. Lean Manufacturing as a Tool for Increasing Labor Productivity at The Enterprise. E3S Web of Conferences, Volume 124, 04015

Konakhina, I.A., Konakhin, A.M., Shinkevich, O.P., 2011. Thermodynamic Analysis of the System for Collection and Re-use of Condensate. Bulletin of Ivanovo State Energy University, Volume 2, pp. 11-14

Kosasih, E.A., Ruhyat, N., 2016. Combination of Electric Air Heater and Refrigeration System to Reduce Energy Consumption: A Simulation of Thermodynamic System. International Journal of Technology, Volume 7(2), pp. 288-295

Kusrini, E., Kartohardjono, S., 2019. Revolutions in Chemical Engineering through the Development of Materials Science and Product Design for Sustainable Energy and Future Applications. International Journal of Technology, Volume 10(3), pp. 438-442 
Kusumah, A.S., Hakim, I.I., Sukarno, R., Rachman, F.F., Putra, N., 2019. The Application of Ushape Heat Pipe Heat Exchanger to Reduce Relative Humidity for Energy Conservation in Heating, Ventilation, and Air Conditioning (HVAC) Systems. International Journal of Technology, Volume 10(6), pp. 1202-1210

Nasruddin, N., Nasution, S., Aisyah, N., Surachman, A., Wibowo, A.S., 2018. Exergy Analysis and Exergoeconomic Optimization of a Binary Cycle System using a Multi Objective Genetic Algorithm. International Journal of Technology, Volume 9(2), pp. 275-286

Nazmeen, Y.G., Komahina, I.A., 2002. Heat and Power Systems and Energy Balances of Industrial Enterprises. Moscow, Russia: MEI Publishing House

Patrascu, R., Minciuc, E., 2012. Complex Analysis of Recuperation of Energy Potential of Secondary Energy Resources (SER) in a Defined Contour. Politechnica University of Bucharest Scientific Bulletin, Series C: Electrical Engineering and Computer Science, Volume 74, pp. 293-306

Shkrabets, F.P., Berdnyk, V.V., 2016. Secondary Power Resources of the Fuel and Energy Complex in Ukraine. Mechanics, Materials Science \& Engineering Journal, Volume 3(2), pp. $150-155$

Ulum, B., Nurrohman, N., Ambarita, E., Gaos, Y.S., 2017. Energy and Exergy Analysis of Mount Salak Geothermal Power Plant Unit 1-2-3. International Journal of Technology, Volume 8(7), pp. 1217-1228 